\title{
Problem Based Learning Through Modeling and Simulation of Unmanned Vehicles
}

\section{Dr. Lifford McLauchlan, Texas A\&M University, Kingsville}

Dr. Lifford McLauchlan completed his Ph.D. at Texas A\&M University, College Station. After spending time in industry, he has returned to academia. He is an associate professor at Texas A\&M University Kingsville in the Electrical Engineering and Computer Science Department. His main research interests include controls, robotics, education, adaptive systems, intelligent systems, signal and image processing, biometrics and watermarking. He is the current chair of the ASEE Ocean and Marine Engineering Division and is a senior member of IEEE.

Dr. Mehrube Mehrubeoglu, Texas A\&M University, Corpus Christi Jayson Durham, SPAWAR Systems Center Pacific (SSC Pacific) 


\title{
Problem Based Learning through Modeling and Simulation of Unmanned Vehicles
}

\begin{abstract}
Problem based learning has been shown to increase student excitement and attention which will increase student understanding of course material and concepts. With the high cost of large scale underwater, land and air vehicles, the use of modeling and simulation capabilities becomes more important for university programs. Autonomous Unmanned Vehicle (AUV) Workbench was developed at the Naval Postgraduate School as a modeling and simulation environment to enable physics based real time simulation of autonomous vehicles, such as unmanned surface vehicles (USV), unmanned underwater vehicles (UUV) and unmanned aerial vehicles (UAV). Vehicle missions can also be replayed for further study. ${ }^{1-5}$
\end{abstract}

At Texas A\&M University-Kingsville and Texas A\&M University-Corpus Christi, a lab exercise for multiple vehicles has been created for the students to illustrate waypoint navigation and control for unmanned surface and air vehicles. Two versions were developed, an abbreviated version for the freshman students in introductory courses at the two universities, and a more extensive one for the senior students at Texas A\&M University-Kingsville. By enabling a visual representation of the effects of the control algorithm in the simulated actions, freshman students gain a larger scale understanding of more advanced theoretical concepts that they will learn during their junior and senior years, thereby allowing the students to gain insights into how the theory in various undergraduate classes may be used in applications. The seniors in the undergraduate linear controls course at Texas A\&M University-Kingsville can investigate different controllers such as Proportional Integral Derivative (PID) in the AUV Workbench environment, thus enabling students to see how the control of the vehicle is affected as the controller is varied.

System-of-Systems Engineering (SOSE) necessitates an increased sharing and interoperability of information. In support of mission-driven SOSE, a critical need exists to support science and technology research and education that provide increased coordination of activities supporting mission driven SOSE. The AUV Workbench simulation environment enhances the student's understanding of modeling systems which in turn helps to continue addressing this need at the university educational level.

\section{Introduction}

Problem based learning (PBL) instruction provides active learning environments for the students in which their interests are increased by keeping students more engaged in the instructional material. ${ }^{6-8}$ AUV Workbench, a virtual environment for autonomous unmanned vehicle simulations, provides a PBL environment for modeling and simulations to replace expensive physical experiments. There is an ongoing recognized need for semantic-interoperability support services that enable virtual teaming within AUV modeling and simulation PBL and mission planning activities. ${ }^{9-11}$ The AUV Workbench simulation "environment facilitates responsive Systems-of-Systems Engineering (SOSE) whereby both developers and end-users are able to collaboratively perform physics-based unmanned AUV simulations to test Sensor-net Self- 
Organization and Control (SenSOC) and other next-generation capabilities within a broad range of potentially unanticipated operational contexts"9 which aids improved mission planning and rehearsal. ${ }^{9-10}$ Modeling and simulation environments such as AUV Workbench present engaging PBL opportunities to introduce students to interactive simulations based on vehicle test data and physics based models thereby supporting science and technology research and education.

The Introduction to Electrical Engineering course at Texas A\&M University-Kingsville was recently replaced by a new freshman seminar course. Under the new course format, students have less time in the lab, as the new structure has two contact hours in the lab/class versus the older structure with one lecture and three lab contact hours. As a response, new assignments were created that the students could perform in a one to two hour time frame. Many of the upper classmen in the Electrical Engineering and Computer Science Department at Texas A\&M University-Kingsville stated that if they had known they would use a specific topic from the Physics, Calculus, or Linear Algebra classes they would have paid more attention to the material when taking the class since they would have some idea how they would use that knowledge in their junior/senior years. With these reasons in mind, a new laboratory exercise involving three dimensional simulations of six degree of freedom physics based models for unmanned vehicles was developed using the Naval Postgraduate School's AUV Workbench ${ }^{1-5}$ which is a freely available simulator for unmanned vehicles. The AUV Workbench uses physics based equations to simulate how the vehicles behave given the planned paths and the specified controllers such as classical Proportional Integral Derivative (PID). Two versions of the assignment were developed, a shorter version for the freshman students in the introductory course and a longer more in depth version for the senior students in the linear control systems course. A few additions to the assignment were introduced in another freshman-level Foundations of Engineering course at Texas A\&M University-Corpus Christi. Results of the assignment from the two universities are included in the Results Section.

\subsection{Literature Survey}

Problem based learning (PBL) instruction generally provides an active learning environment for the students in which the students' interests are increased by keeping students more engaged in the class material. ${ }^{6-8}$ PBL represents a more realistic approach to problem solving that the students will encounter in the work environment, where they will need to discover what they do not know to solve a particular problem, learn this material, and then solve the problem itself. In a classroom or laboratory environment, problem based learning works better if the professors have students study problems that are of concern or interest to them. Students comprehend more when they are more interested in the instructional material of their own volition then when using outside rewards such as grades. ${ }^{8}$ Many students who worked on the AUV assignment described in Section 3 commented that they had fun working on the assignment, although they were actually learning control concepts and looking at simulations as they changed the parameters and vehicles under test.

\subsection{Proposed Method}

This paper describes an assignment that the students were expected to complete in one to two hours in small groups. The assignment illustrates different controls concepts such as waypoint 
navigation commonly used in unmanned vehicle navigation. The students are more engaged in the assignment, since, when they change parameters, they can immediately see the effects by running the simulation again. The students can in this way compare the effects of parameter manipulation in the simulation outcome. The students are introduced to topics in the freshman year that actually use material from various courses most of which they have not taken yet. Students at the senior level start to follow and understand at least in one way how various courses during their undergraduate curriculum fit together supporting the analysis and control of more advanced concepts or applications based on real-world data and models. The organization of this paper is as follows: A summary of the AUV Workbench Simulator is presented in Section 2. The Autonomous Unmanned Vehicle (AUV) Workbench assignment is described in Section 3. Results and Conclusions are summarized in Sections 4 and 5, followed by the Bibliography.

\section{AUV Workbench Simulator}

The AUV Workbench or a similar three dimensional simulation environment allows the students to visually perceive the effects of their actions such as changing waypoints in the planned path, changing vehicles, changing viewpoints, or changing the controller. This visual environment and visualization capability engages the students more in the learning material as these students are presented with immediate feedback. An example mission for the AUV Workbench is the USVBoxtest which puts a simulated unmanned surface vehicle (USV) through a nearly box shaped planned mission path as shown in Figure 1 and with waypoints labeled in Figure 2.

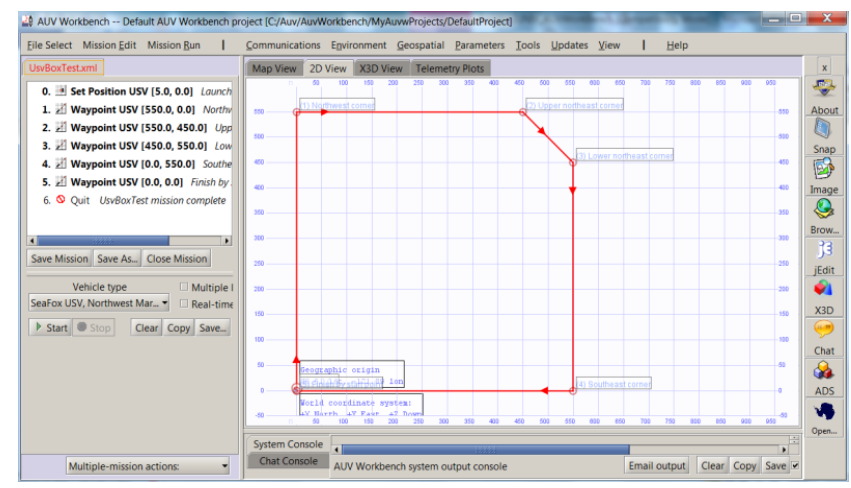

Figure 1. Screenshot from AUV Workbench UsvBoxTest ${ }^{1}$

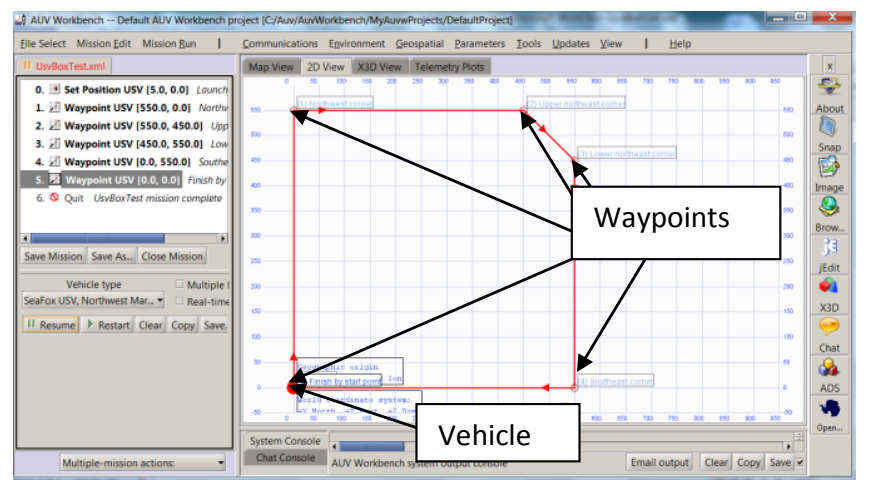

Figure 2. Previous Screenshot with Waypoints Denoted ${ }^{1}$ 
Various views and telemetry data are available for simulated missions in the simulator. "A commonly used technique for path planning for unmanned vehicle path is waypoint navigation. Waypoints define planned locations along the path that the vehicle should traverse... The simulation can be run in accelerated time (simulation time) or in real time. The mission origin can be changed as well as many other parameters such as waypoints. Once the mission starts, the circle that represents the vehicle in the 2D view moves and follows the planned path. The vehicle movement is in the direction of the arrows on the segments." $12-14$ This means that the students receive visual feedback to changes in the planned path when they re-simulate the mission for altered or new mission paths.

Example screenshots from the X3D view are shown in Figure 3. Again the students get immediate feedback as the simulator progresses allowing the visual tracking of the vehicle on a map, a 3D view, or from different viewpoints such as port, starboard, above or below.

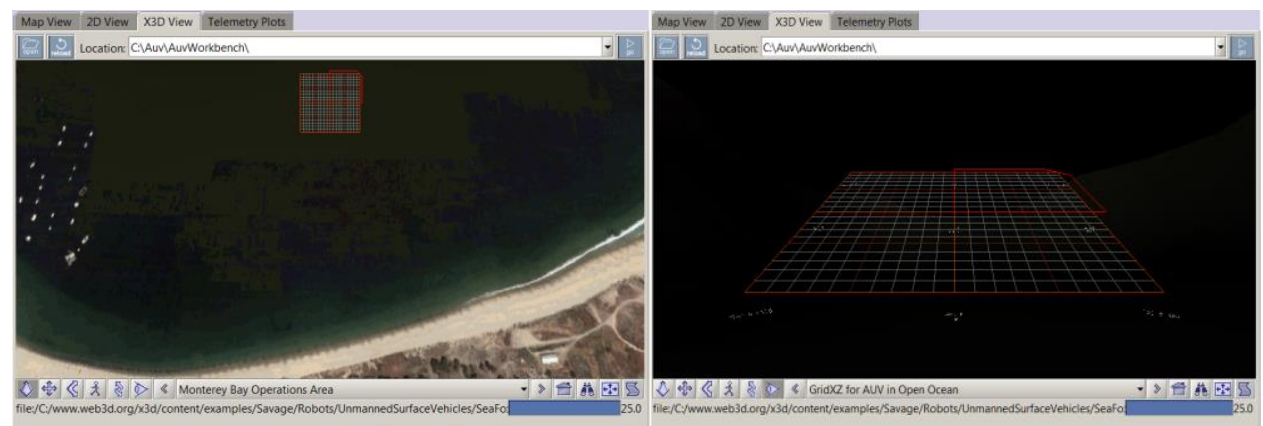

(a)

(b)

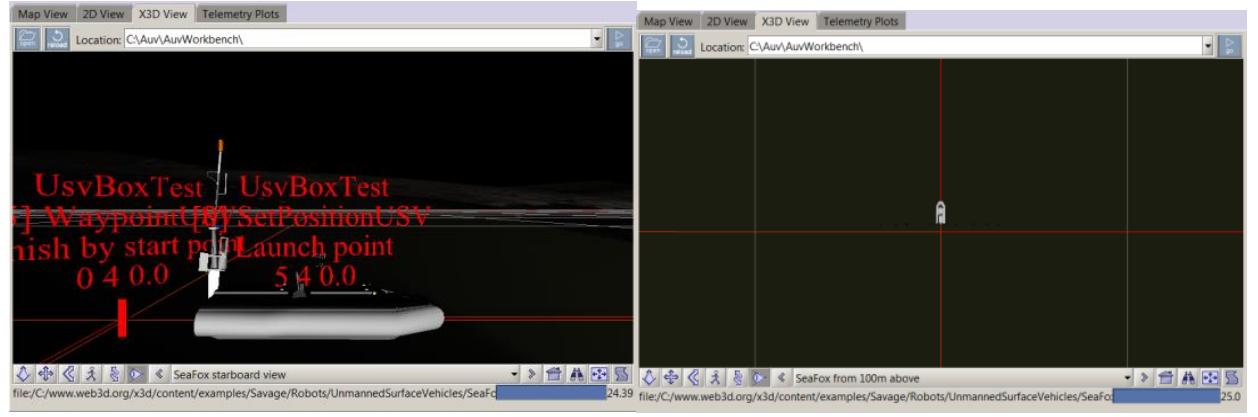

(c)

(d)

Figure 3. Example Screenshots from AUV Workbench UsvBoxTest X3D View Simulation ${ }^{1}$

Figure 3 shows four independent views of the UsBoxTest demonstration mission. ${ }^{1}$ 3(a) is a representation of the operations area, whereas 3(b) shows the grid area. ${ }^{1}$ The starboard view can be seen in 3(c) while 3(d) is a bird's-eye view of the vehicle from $100 \mathrm{~m}$ above. ${ }^{1}$ Telemetry data and plots become available to the user once the mission is stopped or finished. ${ }^{12-14}$ Telemetry plots for missions include data such as real Cartesian $(\mathrm{X}, \mathrm{Y})$ coordinates (see Figure 4), pitch, roll, yaw or the rudder angle to name a few. ${ }^{1-5}$ 


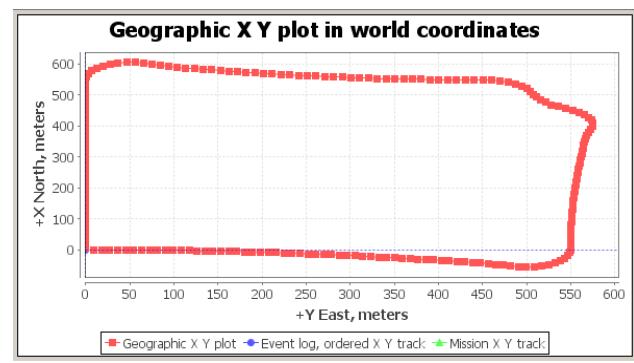

Figure 4. Screenshot of AUV Workbench UsvBoxTest $(\mathrm{X}, \mathrm{Y})$ Coordinates Plot $^{1}$

\section{Assignment on Autonomous Unmanned Vehicle (AUV) Workbench}

The following are some of the questions posed to the students to illustrate or highlight various topics of concern. ${ }^{12-14}$ Some of these questions test students' knowledge, encouraging them to look up and learn relevant material, while some questions test their critical thinking skills. Figure 5 which is found on the AUV Assignment is an example of a screenshot of an UAV Over the Shoulder View. ${ }^{1}$

\section{Selected Questions from the AUV Assignments ${ }^{12-14}$}

1. Why does the telemetry plot for the $X Y$ world coordinates not match the planned path as seen in Figure 1? Note - this demo mission includes data for currents as well as a six degree of freedom physics based model for the vehicle (a set of differential equations describing the vehicle).

2. What is telemetry? What does the rudder telemetry plot mean? Does this plot make sense? You need to compare the plot to the other plots available as well as to the original planned path.

3. What do the other available telemetry plots depict?

4. What courses during your undergraduate degree (see your degree plan) does this simulator use to simulate the vehicle movement, for example two would be Control Systems and Physics.

7. Now change the mission by closing the mission file and opening a new mission file. This time choose the UAVWaypointMission.xml file. Change the UAV vehicle to the Rascal. 


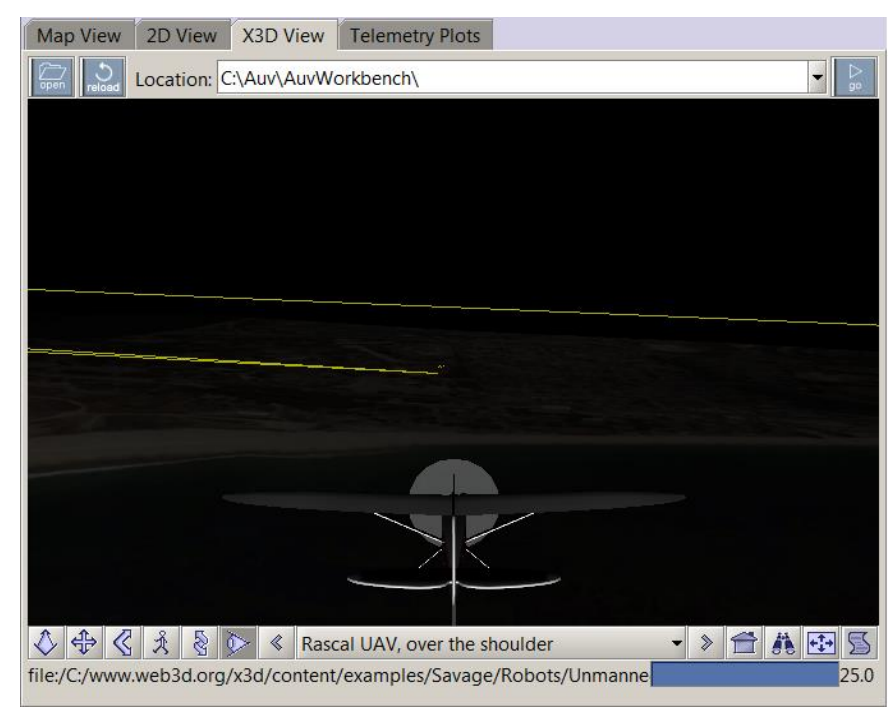

Figure 5. Screenshot of AUV Workbench UAV Over the Shoulder View ${ }^{1}$

8. Why does the telemetry plot for the XY world coordinates not match the planned path.....?

13. What insights does this exercise give you as to how some of the courses you will take during your undergraduate degree may apply to controlling a real system or simulating a real system?

14. What concepts does this simulation exercise illustrate?

Student responses to selected questions are summarized in Tables I and II. Some questions from 1-14 were replaced or modified for the senior linear controls course assignment. Questions 15 and 16 given below were included in the senior version of the assignment only. ${ }^{13}$

15. What controllers can be utilized for the ARIES, Predator and UUV (Unmanned Underwater Vehicle)?

16. During waypoint navigation, the controllers keep the system stable, the waypoints are utilized for path planning. Find two path planning techniques and discuss those. Give your references.

\section{Results}

Student responses are summarized and grouped together in the two Tables I and II. For instance for questions 1 and 8, groups would discuss not being able to perform a 90-degree turn for a real vehicle or that currents would affect the vehicle's response. These were grouped together as vehicle physical limitations and environmental conditions. 
Table I. Summary of Responses to AUV Workbench Assignment, ${ }^{12-14}$ Fall Semester 2012

\begin{tabular}{|c|c|c|}
\hline $\begin{array}{l}\text { Question Number and } \\
\text { Short Description }\end{array}$ & Summary of Responses & $\begin{array}{l}\text { Percentage of Student } \\
\text { Groups Who Answered } \\
\text { Question Correctly }\end{array}$ \\
\hline $\begin{array}{l}\text { 1. XY Coordinates Does } \\
\text { Not Match Planned Path } \\
\text { Exactly for Unmanned } \\
\text { Surface Vehicle }\end{array}$ & $\begin{array}{l}\text { Vehicle physical limitations and } \\
\text { environmental conditions- } \\
\text { such as turning at high speed } \\
\text { while experiencing } \\
\text { environmental conditions such } \\
\text { as currents, wind, air drag, } \\
\text { weather, etc }\end{array}$ & $77.8 \%$ \\
\hline $\begin{array}{l}\text { 2. a) telemetry meaning } \\
\text { b) rudder telemetry } \\
\text { c) does b) make sense }\end{array}$ & $\begin{array}{l}\text { a) Defined telemetry } \\
\text { b) Plots of rudder deflections } \\
\text { c) Yes }\end{array}$ & $\begin{array}{l}\text { a) } 88.9 \% \\
\text { b) } 88.9 \% \\
\text { c) } \quad 66.7 \%\end{array}$ \\
\hline 3. Other telemetry & $\begin{array}{l}\text { Body thrusters, propeller valve, } \\
\text { battery, pitch, yaw and roll }\end{array}$ & $77.8 \%$ \\
\hline 4. Related Courses & $\begin{array}{l}\text { Physics, calculus, differential } \\
\text { equations, robotics, linear } \\
\text { algebra, communications, electric } \\
\text { drives, linear control systems, } \\
\text { fluid mechanics }\end{array}$ & $100 \%$ \\
\hline $\begin{array}{l}\text { 8. XY Coordinates Does } \\
\text { Not Match Planned Path } \\
\text { Exactly for Unmanned } \\
\text { Air Vehicle }\end{array}$ & $\begin{array}{l}\text { Vehicle physical limitations and } \\
\text { environmental conditions- } \\
\text { such as turning at high speed } \\
\text { while experiencing } \\
\text { environmental conditions such } \\
\text { as wind, and other weather }\end{array}$ & $75 \%$ \\
\hline $\begin{array}{l}\text { 13. How courses you } \\
\text { take may apply to real } \\
\text { application }\end{array}$ & $\begin{array}{l}\text { Computer programming, models/ } \\
\text { simulations and controllers based } \\
\text { upon multiple courses such as } \\
\text { Physics, Calculus, Robotics and } \\
\text { Linear Control Systems }\end{array}$ & N/A \\
\hline 14. Illustrated concepts & $\begin{array}{l}\text { Planned paths, data analysis } \\
\text { applying knowledge, autonomous } \\
\text { vehicle control and simulation }\end{array}$ & $\mathrm{N} / \mathrm{A}$ \\
\hline
\end{tabular}


Table II. Summary of Responses to AUV Workbench Assignment ${ }^{13}$ Fall Semester 2012 for Linear Controls Course Specific Questions

\begin{tabular}{|l|l|}
\hline $\begin{array}{l}\text { Question Number and } \\
\text { Short Description }\end{array}$ & Summary of Responses \\
\hline 15. Controllers & $\begin{array}{l}\text { PID, PI. PD, open loop, sliding mode, linear quadratic } \\
\text { regulator (LQR) }\end{array}$ \\
\hline 16. Other Path Planning & $\begin{array}{l}\text { Non-differential GPS, complex vector field, multi-resolution } \\
\text { path planning, Voronoi path planning, approximate cell } \\
\text { decomposition, probabilistic road maps, autonomous } \\
\text { waypoint selection framework (AWSF), waypoint navigation } \\
\text { system (WNS) }\end{array}$ \\
\hline
\end{tabular}

From Table I, most of the students who answered the questions demonstrate an understanding of why the real world XY data did not match the planned path. $88.9 \%$ of the same students were able to define telemetry and what the rudder telemetry meant, but only $66.7 \%$ were able to then take the rudder telemetry and make the connection to which directions the rudder must move to cause the vehicle to move one direction or the other as designated in the planned path. All the student groups who completed the assignment were able to ascertain that many of the math, science, and engineering courses they would take or had taken had a direct bearing on an application such as unmanned vehicle control.

Table II summarizes what controllers the seniors in the linear control systems course were investigating during this assignment and more advanced path planning techniques that could be utilized for the AUV control. Such advanced topics also reinforce the concepts of and the need for life-long learning as found in the requirements for ABET outcomes.

\section{Conclusions}

The success of the AUV Workbench assignment is clearly demonstrated by the student responses to assignment questions as found in Tables I and II as well as comments made to the professors of the courses during the completion of the assignment. This assignment helps support of mission-driven SOSE by reinforcing a student's understanding of modeling systems.

In the future, different physics based models for the same class of vehicles (USV, AUV, UUV) will be simulated. For the senior level course, the controller parameters will need to be modified to reinforce controller concepts taught in the course lecture. This will also introduce the students to XML which the AUV Workbench utilizes for its files. 


\section{Acknowledgements}

The authors would like to acknowledge Dr. Don Brutzman, Dr. Richard Cardenas and Omar Magana for their discussions about and help with the AUV Workbench. The authors also acknowledge the students and their feedback concerning this assignment.

\section{Bibliography}

1. AUV Workbench, https://savage.nps.edu/AuvWorkbench/ accessed January 5, 2013.

2. D. Brutzman, Presentation "NPS AUV workbench: rehearsal, reality, replay for unmanned vehicle operations," NPS Technical Review and Update (TRAU), 25 April 2007, accessed January 4, 2013. http://xmsf.cvs.sourceforge.net/*checkout*/xmsf/AuvWorkbench/documentation/presentations/presentations.html

3. D. Davis and D. Brutzman, "The Autonomous unmanned vehicle workbench: mission planning, mission rehearsal, and mission replay tool for physics-based X3D visualization," $14^{\text {th }}$ International Symposium on Unmanned Untethered Submersible Technology (UUST), Autonomous Undersea Systems Institute (AUSI), Durham New Hampshire, 21-24 August 2005.

4. J. Weekley, D. Brutzman, A. Healey, D. Davis and D. Lee, "AUV workbench: integrated 3D for interoperable mission rehearsal, reality and replay," 2004 Mine Countermeasures \& Demining Conference: Asia-Pacific Issues \& Mine Countermeasures (MCM) in Wet Environments, Australian Defense Force Academy, Canberra Australia, 9-11 February 2004.

5. D. Brutzman, "Autonomous unmanned vehicle workbench (AUVW) rehearsal and replay: mapping diverse vehicle telemetry outputs to common XML data archives," $15^{\text {th }}$ International Symposium on Unmanned Untethered Submersible Technology (UUST), Autonomous Undersea Systems Institute (AUSI), Durham New Hampshire, 1922 August 2007.

6. L. McLauchlan, "Design-oriented course in microprocessor based controls," Proc. of the 2007 ASEE Annual Conference and Exposition, AC2007-2675, Honolulu, HI, pp. 1-11, June 24-27, 2007.

7. M. Prince, "Does Active Learning Work? A Review of the Research," Journal of Engineering Education, pp. 223-231, July 2004.

8. R. Pucher, A. Mense, and H. Wahl, "How to Motivate Students in Project Based Learning," $6{ }^{\text {th }}$ IEEE Africon Conference in Africa, vol. 1, pp. 443-446, Oct. 2-4, 2002.

9. J. Durham, M. Mehrubeoglu, D. Carter, R. McBee, and L. McLauchlan, "Support for Flight Trajectories and Video Capture: Initial Results Using a Free Open Source Flight Simulator," Earth \& Space 2010 Conference - The 12th ASCE Aerospace Division Biennial International Conference on Engineering, Science, Construction and Operations in Challenging Environment, Honolulu, HI, pp. 1941-8, March 14-17, 2010.

10. J. Durham, M. Mehrubeoglu, and L. McLauchlan, "Interoperable Open-Source Sensor-Net Frameworks With Sensor-Package Workbench Capabilities: Motivation and Exploratory Results," Proc. of 15th ICCRTS International Command and Control Research and Technology Symposium, Santa Monica, California, pp. 1-8, June 22-24, 2010.

11. J. Durham, L. McLauchlan, and R. Yuster, "Enabling a common and consistent enterprise-wide terminology: an initial assessment of available tools," Proc. of 2008 IEEE/WIC/ACM International Conference on Web Intelligence and Intelligent Agent Technology, Sydney, Australia, pp. 544-548, Dec. 9-12, 2008.

12. L. McLauchlan, Autonomous Unmanned Vehicle (AUV) Workbench Assignment for the Freshman course Learning in Global Context I, Texas A\&M University-Kingsville, 2012.

13. L. McLauchlan, Autonomous Unmanned Vehicle (AUV) Workbench Assignment for the Senior course Linear Control Systems, Texas A\&M University-Kingsville, 2012.

14. L. McLauchlan and M. Mehrubeoglu, Autonomous Unmanned Vehicle (AUV) Workbench Assignment for the Freshman course Foundations of Engineering, Texas A\&M University-Corpus Christi, 2012. 